\title{
An Overview of the Grapefruit Market in the U.S. ${ }^{1}$
}

\author{
Lijun (Angelia) Chen and Lisa House ${ }^{2}$
}

\section{Introduction}

Global grapefruit production has been increasing steadily in the recent decade, reaching a historical record of 6.8 million metric tons (MT) in 2018/2019 (Figure 1) -a change from the drastic decreases between 2003 and 2006. These changing trends correspond with changing dynamics in the industry. Production in the United States, once the dominant producer of grapefruit, fell with the spread of Huanglongbing (HLB, or citrus greening) combined with devastating hurricanes. China stepped in to fill this decrease, with expanding grapefruit production starting in 2007. When interpreting these trends, however, it is critical to note that data associated with the grapefruit industry (e.g., Foreign Agriculture Service of the United States Department of Agriculture, USDA-FAS, and Food and Agriculture Organization of the United Nations, FAO) do not distinguish between grapefruit and pomelo. "Grapefruit" production and consumption are mostly attributed to pomelo in China, which falls under the grapefruit category in other countries (Heng et al. 2017). This information is important because China's surging demand and supply of pomelo have driven up the global consumption and production of the statistical category of grapefruit even though the rest of the world has seen a downtrend. In addition, despite being the current largest grapefruit producer, China does not dominate the international trade market because its domestic production is mainly used to fulfill the domestic demand for pomelo.
Grapefruit (incl. pomelo) production in selected countries, 1990 - 2018

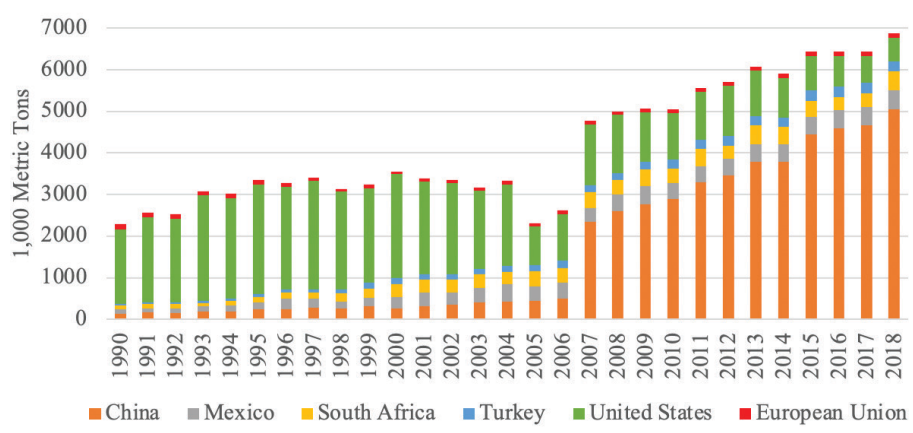

Figure 1. Grapefruit (incl. pomelo) production in selected countries, 1990-2018.

Credits: Food and Agriculture Organization-FAOSTAT, http://www. fao.org/faostat/en/\#data/QC

\section{Fresh Fruit Market in the U.S.}

Citrus fruit is one of the most-consumed fresh fruits in the U.S., accounting for $14 \%$ of total fresh fruits available for Americans to eat in 2018 (58.3 lb per capita, after adjusting for losses) (Blazejczyk 2020). Based on retail weight (per capita consumption in pounds), the top five most-consumed fresh fruits in 2018 were bananas (28.2 $\mathrm{lb})$, apples $(16.9 \mathrm{lb})$, oranges $(8.2 \mathrm{lb})$, grapes $(8.1 \mathrm{lb})$, and avocados (8.0 lb) (Statista 2018a). As a result of economic growth, productivity increases, and heightened awareness of health benefits associated with fruit consumption, per capita consumption of fresh fruit in the U.S. reached 115.1 $\mathrm{lb}$ in 2018, showing a 15\% increase compared with 2008 (Statista 2018b). The diversity of fresh fruit consumption has also been on the rise over the past 30 years. For example, consumption of avocados and blueberries has

1. This document is FE1095, one of a series of the Food and Resource Economics Department, UF/IFAS Extension. Original publication date May 2021. Visit the EDIS website at https://edis.ifas.ufl.edu for the currently supported version of this publication.

2. Lijun (Angelia) Chen, postdoctoral associate, Food and Resource Economics Department; and Lisa House, professor and chair, Food and Resource Economics Department; UF/IFAS Extension, Gainesville, FL 32611.

The Institute of Food and Agricultural Sciences (IFAS) is an Equal Opportunity Institution authorized to provide research, educational information and other services

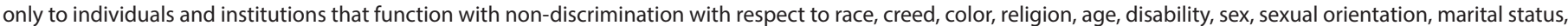

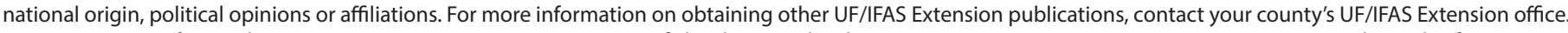
U.S. Department of Agriculture, UF/IFAS Extension Service, University of Florida, IFAS, Florida A \& M University Cooperative Extension Program, and Boards of County Commissioners Cooperating. Nick T. Place, dean for UF/IFAS Extension. 
increased in light of perceived health benefits (Fulgoni et al. 2013; Evans and Ballen 2014). In addition, the market has seen increased consumer preferences for tropical fruits such as mangoes, papayas, and pineapples. Per capita availability of the aforementioned fruits has skyrocketed more than $250 \%$ compared with the average level in the 1990s (USDA-ERS 2020). Other fruits have shown declines, including grapefruit, peaches and nectarines, plums, and oranges. Many reasons may explain why these fresh fruits have become less in demand over the years, including intensified competition in the fresh fruit market generated by diverse choices, the thriving 100\% fruit juice market as an alternative to consuming fresh fruit, and changing consumer preferences and dietary patterns.

Although Americans' fresh fruit consumption is much higher than in the last century, it is still below the recommended fruit intake given by the Dietary Guidelines (Dietary Guidelines Advisory Committee). Loss-adjusted Food Availability Data (USDA-ERS 2020) shows that Americans, on average, consumed 0.5 cup-equivalents of fresh fruit and 0.2 cup-equivalents of fresh fruit juice per person per day in 2017, less than half of the recommended 2 cup-equivalents based on a 2,000-calorie diet.

\section{Grapefruit Market in the U.S. \\ Grapefruit Production and Trade}

The most recently updated report on world markets and trade of citrus by USDA-FAS (2020) shows that grapefruit production in the U.S. declined in the last two decades until recently, with a more than $10 \%$ uptick in both the 2018/19 and 2019/20 seasons. Total U.S. production in 2019/20 reached $582 \mathrm{MT}$, with increased production in Florida, Texas, and California (USDA-FAS 2020). The previous decline in U.S. grapefruit production before $2018 / 19$ is also associated with the plummeting bearing acreage since the 1996/97 season (Figure 2) and declining yield in the past decade, caused by unfavorable weather and citrus greening (USDA-FAS 2018).

Florida leads citrus fruit production in the U.S., followed by California and Texas. Although Arizona also produces grapefruit, the output is so low that the USDA stopped including it in their data in 2009/10. The major grapefruitproducing states are affected by agricultural disasters at different levels. Comparing the bearing acreage data in $2018 / 19$ to that in $1980 / 81$, Florida grapefruit acreage had decreased by nearly $80 \%$. Due to plant diseases, predominantly citrus greening, Florida's yield was 7.1 MT per acre in the 2018/19 season. Texas and California have both managed to maintain a yield level two times higher than Florida (USDA-ERS 2020). Before the emergence of citrus greening, the five-year average yield of Florida grapefruit between 1999 and 2004 was 19.2 MT per acre.

Grapefruit bearing acreage of top producing states in the U.S., 1980-2018

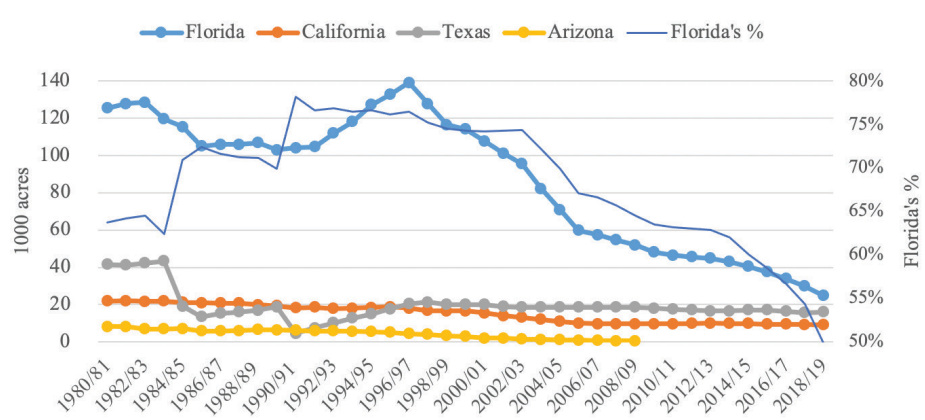

Figure 2. Grapefruit bearing acreage of top producing states in the U.S., 1980-2018.

Credits: USDA-ERS. Fruit and Tree Nut Data. Yearbook tables. Accessed on March 2, 2020. Available at https://www.ers.usda.gov/dataproducts/fruit-and-tree-nut-data/

Despite progressively declining exports due to decreased domestic production and a weakened currency, the U.S. remains a principal exporter of grapefruit, competing with South Africa, Turkey, and China (pomelos) in the international trade market. Based on 2018 customs values retrieved from the U.S. Department of Commerce, the top four fresh grapefruit (i.e., raw fruits) importers are Japan (\$21.6 million), Canada (\$15.6 million), South Korea (\$9.8 million), and France ( $\$ 6.8$ million). In addition to exporting, the U.S. imports fresh grapefruit from Mexico, Africa, Peru, and Israel in different amounts across years. Although the U.S. remains a net exporter, the trade surplus in grapefruit has been shrinking over the past 20 years due to the continuous decline in exports, reaching the smallest surplus yet in 2018 (45 MT) (Figure 3). As for grapefruit juice (Figure 4), the trade surplus has been decreasing since 2004, with a deficit in 2018 due to soaring imports after Hurricane Irma and subsequent production losses within the Florida industry. Major international consumers of U.S. grapefruit juice include, but are not limited to, the Netherlands ( $\$ 8.7$ million), Canada ( $\$ 8.2$ million), Japan ( $\$ 6.0$ million), and Belgium ( $\$ 2.8$ million). As a top fresh grapefruit importer, France also imports a large amount of U.S. grapefruit juice indirectly from other European countries (such as Belgium and the Netherlands, where the two major trading ports, Antwerp and Rotterdam, are located). Although China's fresh grapefruit consumption is primarily fulfilled by domestic pomelo production, its increasing demand for grapefruit juice has made China a major importer from the U.S., yielding a customs value of \$1.66 million in 2018. 
Fresh grapefruit utilization, exports and imports (Metric Tons), 2000-2019

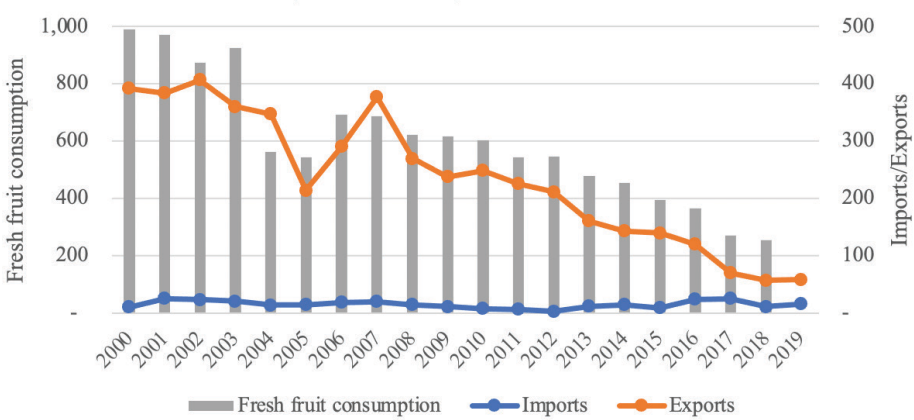

Figure 3. U.S. fresh grapefruit utilization, exports and imports (Metric Tons), 2000-2019.

Credits: U.S. Department of Commerce. Data compiled by the Economic and Market Research Department at the Florida Department of Citrus.

Processed grapefruit utilization, juice exports and imports (Equivalent Metric Tons of Raw Fruit), 2000-2019

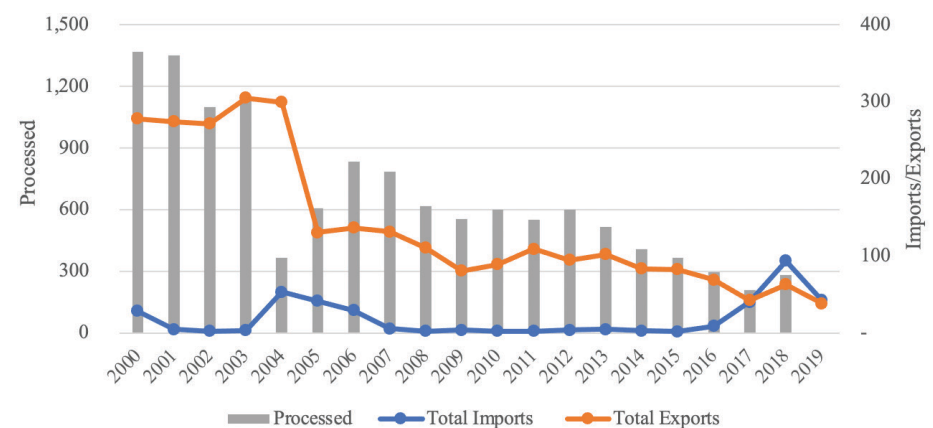

Figure 4. U.S. processed grapefruit (juice) utilization, juice exports and imports (Equivalent Metric Tons of Fresh Fruit), 2000-2019.

Credits: U.S. Department of Commerce. Data compiled by the

Economic and Market Research Department at the Florida Department of Citrus

\section{Grapefruit Consumption and Price}

U.S. consumers eat both red (pink) and white grapefruit. However, white grapefruit is generally less popular among U.S. consumers. The quantity of red grapefruit entering a processing plant is slightly more than, or about the same as, the quantity entering the fresh fruit market in recent years. On the other hand, less than $30 \%$ of white grapefruit is consumed unprocessed. In the crop year 2018/19, fresh use made up $43 \%$ of total grapefruit utilization regardless of color (USDA-NASS 2018). The U.S. is the top consumer of processed grapefruit (i.e., grapefruit juice) and the fourth largest consumer of fresh grapefruit, following China, the European Union, and Mexico.

In 2018 , the average U.S. citizen consumed $1.5 \mathrm{lb}$ of grapefruit, which is $80 \%$ below the average consumption level in the $1970 \mathrm{~s}$ of $8.2 \mathrm{lb}$. Total U.S. fresh grapefruit consumption is down to 214 MT (USDA-ERS). Meanwhile, the retail price of fresh grapefruit has surged more than twofold compared with two decades ago (Statista 2019). In addition to the aforementioned decreased production, other factors, such as lower levels of U.S. supplies and increased cost associated with tree maintenance and plant disease management, have also caused grapefruit prices to increase.

\section{U.S. Grapefruit Consumer Survey}

A comprehensive understanding of U.S. consumers' perceptions about grapefruit is critical to help producers and marketers to devise effective marketing communications and boost domestic grapefruit consumption. The Florida Department of Citrus, in conjunction with the University of Florida's Florida Agricultural Market Research Center, has developed and maintained a national online survey annually to investigate and track consumer perspectives about U.S. grapefruit since 2015. The survey instrument is delivered to female primary grocery shoppers ${ }^{\star \star}$ above 20 years of age, in households with income in the top $70 \%$ of the country. A validation question is used to screen out respondents who fail to answer questions carefully in order to ensure data quality (Jones, House, and Gao 2015). Demographic information, such as age, education, and household income, are also collected. A sample of 1,098 valid responses was achieved in 2019. A brief statistical summary of consumer demographics is shown in Table 1. Respondents are mostly in their 40s or 50s, have college degrees, and come from middle-income households. In general, respondents had positive perceptions about grapefruit (e.g., grapefruit supports the immune system [60\%], helps with weight loss [35\%], is low in calories [40\%], provides antioxidants [31\%], and is devoid of fat, cholesterol, and sodium [28\%]).

Active grapefruit consumers (i.e., those who have purchased grapefruit in the past six months) account for $20 \%$ of the sample, showing a small decline compared with the share of active consumers in 2018 (23\%). Among these active consumers, $33 \%$ consumed grapefruit at least once a week. A closer look at composition (Figure 5) from 2017 to 2019 reveals that the percentage of the least active consumers (who consumed grapefruit less than once a month) is growing. Active consumers attributed grapefruit consumption to three major reasons: "like it and eat it regularly" (50\%), "help with weight loss" (43\%), and "help with eating healthier" (36\%). Grapefruit purchases usually occur in the summer (38\%). Consumers tend to prefer pink/red grapefruit (73\%).

Lapsed consumers, who did not purchase grapefruit in the last six months but had purchased grapefruit in the past two years, constituted 32\% of the total sample size in 2019 . Multiple reasons explain why a consumer has not purchased grapefruit in the past six months (e.g., prefer other 
juices and fruit [28\%], don't like the taste [25\%], medication interactions $^{* * *}[19 \%]$, and inconvenient to eat $\left.[6 \%]\right)$.

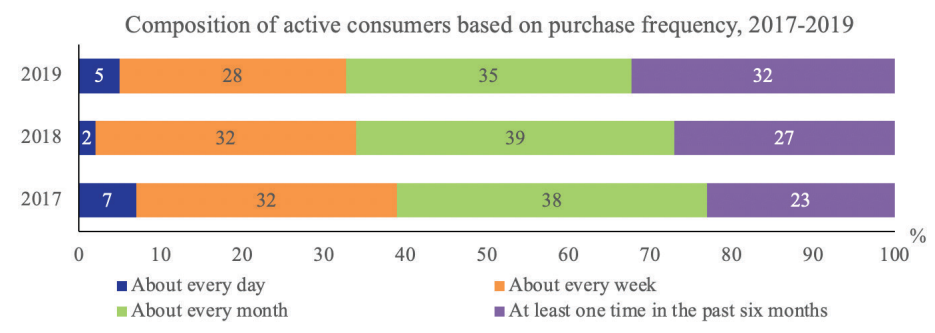

Figure 5. Composition of active consumers based on purchase frequency, 2017-2019.

Credits: Survey data calculated by authors

Lost consumers, accounting for $45 \%$ of the sample, are defined as those who had not purchased grapefruit in the past two years. Among the three groups of grapefruit consumers, lost consumers were least likely to return to the market. Lapsed consumers were comparatively more likely to repurchase grapefruit but their decision remains uncertain. On the contrary, $63 \%$ of active consumers indicated that they would definitely purchase grapefruit. Three consumer groups' willingness to repurchase grapefruit is shown in Figure 6.

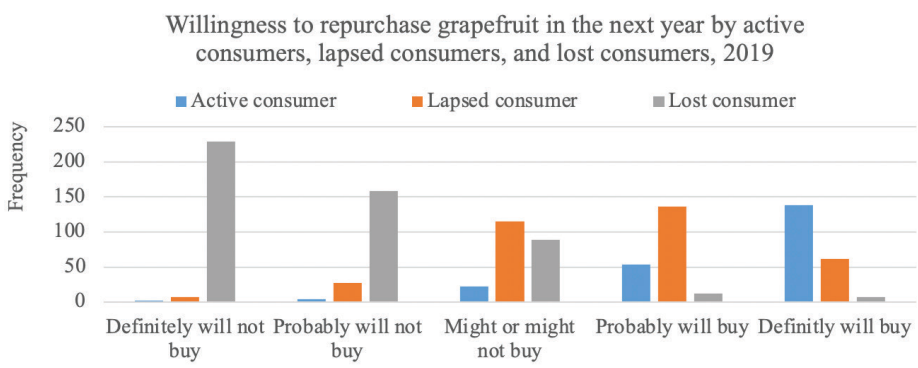

Figure 6 . Willingness to repurchase grapefruit in the next year by active consumers, lapsed consumers, and lost consumers, 2019. Credits: Survey data calculated by authors

Potential consumers, defined as consumers who have purchased in the past two years or intended to purchase grapefruit in the future, accounted for $54 \%$ of the sample. Of those, 39\% reported that knowing where their grapefruit is grown is important, and half of the respondents recognized Florida and California as grapefruit suppliers. In addition, $46 \%$ of the respondents indicated that they would be more willing to purchase grapefruit from Florida, and $32 \%$ were willing to pay more for Florida grapefruit (Figure 7). When asked why they preferred Florida grapefruit, consumers indicated positive perceptions such as Florida grapefruit is juicier (18\%), sweeter (17\%), and available all year round (12\%). Respondents also rated important aspects that could improve their likelihood of consuming Florida grapefruit. These included price promotions, improved taste, better knowledge of best purchase season and health benefits, and labels that clearly indicate origins.
Consumer preference for Florida grapefruit, 2019

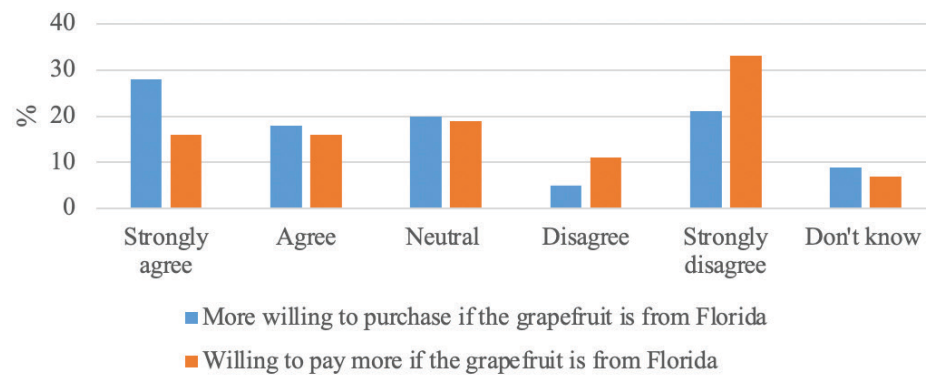

Figure 7. Consumer preference for Florida grapefruit, 2019. Credits: Survey data calculated by authors

Consumption occasions of grapefruit among U.S. consumers have changed as well. While breakfast and snacks remain the top two consumption occasions, the portion of U.S. consumers not knowing when to eat grapefruit has increased to $28 \%$ in 2019 from $24 \%$ in 2017 . In order to explore the possible market potential for grapefruit, the 2019 survey also investigated consumer preference for grapefruit-flavored beverages (Figure 8). The most popular option is smoothie or juice with fresh grapefruit juice, with $60 \%$ of the respondents indicating they were willing to try, followed by alcoholic cocktail infused with fresh grapefruit juice and grapefruit-flavored beer attracting $47 \%$ and $29 \%$ of the respondents, respectively.

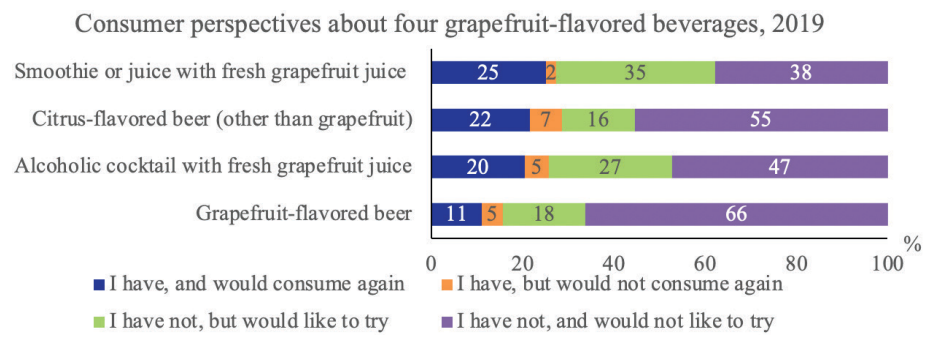

Figure 8. Consumer perspectives about four grapefruit-flavored beverages, 2019.

Credits: Survey data calculated by authors

Finally, in an effort to compare profiles of grapefruit consumers, pairwise t-tests on demographic characteristics were carried out among active consumers, lapsed consumers, and lost consumers (Table 1). Results show that demographic differences between active and lapsed consumers are minor, but active and lapsed consumers are considerably different from lost consumers. Active consumers are least likely to have health issues such as hypertension and high cholesterol. Compared to active and lapsed consumers, lost consumers are significantly more likely to have high cholesterol issues, a medical condition that often requires medications that interact with grapefruit. Lost consumers also tend to be older, come from less wealthy households, and be from smaller communities. 


\section{Summary}

The U.S. grapefruit industry has been facing fierce challenges in both production and consumption. Natural disasters (e.g., hurricanes) and the rapid spread of citrus greening disease significantly damaged Florida's grapefruit groves, which used to dominate the country's production. While horticultural scientists continue to work on potential solutions to the greening issue, tremendous efforts have been made to sustain tree health and maintain fruit quality, driving up production costs which contribute to price increases for grapefruit in grocery stores. However, this is not the only reason why consumers are leaving the market. Intensified competition from different fruits, consumers' changing preferences, and interactions between medications and grapefruit have all contributed to the decline of consumption. Current active consumers have the strongest inclination to continue purchasing grapefruit while lost consumers, who are older and more likely to have health issues requiring medications that interact with grapefruit, are unlikely to revisit the grapefruit market. Although lapsed consumers are hesitant and lack recent consumption experience, it may be possible to win them back through timely marketing communication. Given the recognition of Florida as a preferred grapefruit supplier, marketing strategies focused on enhancing Florida grapefruit's image (e.g., higher quality) could greatly benefit growers and the industry. Another potential way to boost grapefruit consumption is to promote grapefruit-flavored beverages, such as fresh grapefruit juice-infused smoothies and cocktails.

\section{References}

Blazejczyk, A. 2020. "Citrus Fruits Accounted for 14 Percent of Fresh Fruits Available for Americans to Eat in 2018." USDA-ERS. Accessed on January 14, 2021. https:// www.ers.usda.gov/amber-waves/2020/august/citrus-fruitsaccounted-for-14-percent-of-fresh-fruits-available-foramericans-to-eat-in-2018/

Evans, E. A., and F. H. Ballen. 2014. An Overview of U.S. Blueberry Production, Trade, and Consumption, with Special Reference to Florida. FE952. Gainesville: University of Florida Institute of Food and Agricultural Sciences. https:// edis.ifas.ufl.edu/fe952

Food and Agriculture Organization. 2021. "FAOSTAT." Accessed on March 23, 2021. http://www.fao.org/faostat/ en/\#data/QC

FDA. 2017. "Grapefruit juice and some drugs don't mix." https://www.fda.gov/consumers/consumer-updates/ grapefruit-juice-and-some-drugs-dont-mix
Fulgoni, V. L., M. Dreher, and A. J. Davenport. 2013. "Avocado consumption is associated with better diet quality and nutrient intake, and lower metabolic syndrome risk in U.S. adults: Results from the National Health and Nutrition Examination Survey (NHANES) 2001-2008." Nutrition Journal 12 (1): 1.

Heng, Y., H. Kim, and L. House. 2020. An Overview of the Grapefruit Market in South Korea. FE1003. Gainesville: University of Florida Institute of Food and Agricultural Sciences. https://edis.ifas.ufl.edu/fe1003

Jones, M., L. House, and Z. Gao. 2015. "Respondent Screening and SARP: Testing Quarantining Methods for Better Data Quality in Web Panel Surveys." Public Opinion Quarterly 79 (3): 687-709.

Statista. 2018a. "Per Capita Consumption of Fresh Fruit in the United States in 2018, by Selected Fruit Type (in Pounds)." https://www.statista.com/statistics/257239/percapita-consumption-of-fresh-fruit-in-the-us-by-fruit-type/

Statista. 2018b. "Per Capita Consumption of Fresh Fruit in the Unites States from 2000 to 2018 (in Pounds)." https://www.statista.com/statistics/257127/ per-capita-consumption-of-fresh-fruit-in-the-us/

Statista. 2019. "Retail Price of Grapefruits in the United States from 1995 to 2019." https://www.statista.com/statistics/236885/ retail-price-of-grapefruits-in-the-united-states/

U.S. Department of Commerce. 2021. Accessed on March 23, 2021. https://data.commerce.gov/ browse?federation_filter $=1066$

USDA-ERS. 2020. "Fruit and Tree Nut Data." Yearbook Tables. Accessed on March 2, 2020. https://www.ers.usda. gov/data-products/fruit-and-tree-nut-data/

USDA-ERS. 2018. "Fruit and Vegetable Prices Data." https://www.ers.usda.gov/data-products/ fruit-and-vegetable-prices/

USDA-ERS. 2020. "Loss-Adjusted Food Availability." Food Availability (Per Capita) Data System. https://www.ers. usda.gov/data-products/food-availability-per-capita-datasystem/food-availability-per-capita-data-system/\#LossAdjusted Food Availability

USDA-FAS. 2018. Citrus: World Markets and Trade. Washington, D.C.: United States Department of Agriculture, 
Foreign Agricultural Service. https://downloads.usda.

library.cornell.edu/usda-esmis/files/w66343603/3j333266z/

j098zb51z/citruswm-07-26-2018.pdf

USDA-FAS. 2020. Citrus: World Markets and Trade. Washington, D.C.: United States Department of Agriculture, Foreign Agricultural Service. https://apps.fas.usda.gov/ psdonline/circulars/citrus.pdf

USDA-NASS (National Agricultural Statistics Service). 2018. Citrus Fruit 2018 Summary. https://www.nass.usda. gov/Publications/Todays_Reports/reports/cfrt0818.pdf

U.S. Department of Health and Human Services, and U.S. Department of Agriculture. 2015-2020 Dietary Guidelines for Americans. $8^{\text {th }}$ edition. https://health.gov/sites/default/ files/2019-09/2015-2020_Dietary_Guidelines.pdf 
Table 1. Summary statistics of respondent demographics.

\begin{tabular}{|c|c|c|c|c|c|c|}
\hline & Active Consumer & $\begin{array}{l}\text { Lapsed } \\
\text { Consumer }\end{array}$ & Lost Consumer & $\begin{array}{l}\text { Active versus } \\
\text { Lapsed }\end{array}$ & $\begin{array}{c}\text { Active versus } \\
\text { Lost }\end{array}$ & $\begin{array}{c}\text { Lapsed versus } \\
\text { Lost }\end{array}$ \\
\hline & \multicolumn{3}{|c|}{ Mean (S.D.) } & \multicolumn{3}{|c|}{$t$-statistics } \\
\hline $\mathrm{Age}^{\mathrm{a}}$ & $48.66(14.86)$ & $48.80(14.24)$ & $50.65(15.37)$ & -0.1079 & $-1.615^{*}$ & $-1.7776 *$ \\
\hline Education & $2.00(0.57)$ & $1.94(0.6)$ & $1.89(0.67)$ & 1.1063 & $1.953 *$ & 1.0077 \\
\hline $\begin{array}{l}\text { Household } \\
\text { income }\end{array}$ & $4.25(1.27)$ & $4.18(1.22)$ & $3.90(1.25)$ & 0.5716 & $3.3747 * * *$ & $3.2515^{* * *}$ \\
\hline Household size & $2.75(1.37)$ & $2.68(1.38)$ & $2.57(1.41)$ & 0.5748 & 1.5792 & 1.1307 \\
\hline $\begin{array}{l}\text { Neighborhood } \\
\text { size }\end{array}$ & $3.02(1.83)$ & $3.1(1.8)$ & $3.4(1.86)$ & -0.5005 & $-2.5068 * *$ & $-2.3136 * *$ \\
\hline Hypertension $^{b}$ & $0.28(0.45)$ & $0.35(0.48)$ & $0.4(0.49)$ & $-1.8466^{*}$ & $-3.0684 * * *$ & -1.3071 \\
\hline Diabetes $^{b}$ & $0.14(0.35)$ & $0.17(0.37)$ & $0.17(0.37)$ & -0.836 & -0.9016 & -0.0202 \\
\hline High cholesterol $^{b}$ & $0.23(0.42)$ & $0.24(0.43)$ & $0.31(0.46)$ & -0.2011 & $-2.0103 * *$ & $-2.1028 * *$ \\
\hline Obesity $^{b}$ & $0.18(0.38)$ & $0.22(0.42)$ & $0.22(0.41)$ & -1.2833 & -1.1901 & 0.1982 \\
\hline Sample size & $N=220$ & $N=347$ & $N=495$ & $N=567$ & $N=715$ & $N=842$ \\
\hline
\end{tabular}

Source: Survey data calculated by authors.

${ }^{a}$ Continuous variable.

${ }^{\mathrm{b}}$ Dummy variable. Education attainment is a categorical variable; $1=$ less than high school, $2=$ college or university, $3=$ post-graduate. Household income was measured categorically; $1=$ less than $\$ 15,000,2=\$ 15,000-\$ 35,000,3=\$ 35,000-\$ 50,000,4=\$ 50,000-\$ 70,000,5=\$ 75,000-\$ 100,000$, and $6=$ more than $\$ 100,000$. Neighborhood size is a categorical variable; $1=$ more than 500,000 inhabitants, $2=100,000-499,999$ inhabitants, $3=50,000-99,999$ inhabitants, $4=$ 20,000-49,999 inhabitants, $5=10,000-19,999$ inhabitants, $6=1,000-9,999$ inhabitants, and $7=$ fewer than 1,000 inhabitants. Active consumers are those who reported purchasing grapefruit in the past six months. Lapsed consumers are those who have purchased grapefruit in the past two years but did not make purchases in the past six months. Lost consumers are those who have not purchased grapefruit for at least two years.

${ }^{*} p<0.01$

** $p<0.05$

$* * * \mathrm{p}<0.1$ 